\title{
Turning Backs - o espectador está presente?
}

\author{
Rita Vilhena
}

Instituto de Etnomusicologia - centro de estudos em música e dança /

polo da Faculdade de Motricidade Humana da Universidade de Lisboa, Portugal

\begin{abstract}
Does a performance have the potential to intensify the experience in the life of a human being? And what is the level of participation required? Having a performative video installation called "Turning Backs" as a central object of study, this essay will address these and other questions.

This work intends to make an analysis that explores the space of the spectator and the transgression of roles: spectator-performer. "Turning Backs" is a piece that aims at the materialisation of the paradox: we are all included in the exclusion. It is based on a performative video installation, which combines image, body and voice in a scenic device to orchestrate two lines of viewers from two opposing fronts in order to participate. Turned back to each other, the audience is a kind of choral corps commanded by two videos. The two lines of seats have no back and force each viewer to use the back of another as backrest. This situation is a strong allegory of economic co-dependence and still, what I will look at is the condition of the spectator.
\end{abstract}

Keywords: Performance-Participation, Video Installation, Spectator-Performer

\section{Introdução}

Segundo Diana Taylor $^{1}$, nos anos 1960 e 1970 Victor Turner escrevia como é que as populações poderiam aprender a compreender-se umas às outras por meio das suas performances. Contudo para ela, existem outros teóricos que defendem que a performance significa justamente o oposto: o caráter construído das performances sinaliza a sua artificialidade - a performance é a imitação do real. Para Taylor, a problemática desta definição é a desvalorização daquilo que é construído, do que é teatral. E ao mesmo tempo defende a ideia de que a performance destila uma verdade "mais verdadeira" do que a própria vida, vem desde Aristóteles, passando por Shakespeare, Artaud e Grotowski, chegando até ao presente. A performance seria, assim, um evento que se liberta das expectativas e das economias/pressões sociais de agir de acordo com a "normalidade". Frisando a perspectiva subjectiva, a performance pode ainda ser um processo no qual uma experiência se consuma e o seu sentido pode ser apreendido sempre de um modo relativo, "malgrado todas as tentativas de cristalização do sentido do vivido" ${ }^{2}$. Poderíamos ainda acrescentar que a performance, em geral, não quer fazer sentido ou deixar de fazer sentido; ela performa o sentido como um fazer, o fazer colectivo dos sentidos. Para a contemporânea Eleonora Fabião, artista e intelectual brasileira conceituada, desde 2008 performa nas ruas e se interessa por poéticas e éticas do estranho, do encontro e do precário, a performance passa por: "Se deixar fazer (receptiva) e fazer coisas acontecerem (agenciamentos). A estética é meu meio de entrada (e de saída). A ação poética é aquilo que suspende o conformado, abre as coisas, toca, estranha, deflagra relações raras, rearranja (revela as intra-ações coconstitutivas entre tudo e todos, entre tudo e todxs, entre txdxs)" ${ }^{3}$.

Taylor segue o universo eurocêntrico de Victor Turner para explicar a raiz etimológica francesa "performance" que surge a partir do termo parfournir, "fornecer", "completar", ou "executar completamente". Assim do francês, o termo passou para o inglês como performance, no século XVI. A definição de performance assinala a intenção de transmitir conhecimento, são atos de transferência vitais, de memória e de sentido de identidade. Se pensarmos que uma dança, um ritual, ou uma manifestação exigem uma separação, ou um enquadramento que os diferenciem de outras práticas sociais à sua volta, isso não implica que a performance não seja real ou verdadeira. Turner, em concordância com a teoria clássica de Durkheim, tinha uma visão do ritual como a própria sociedade em acto $^{4}$, como o lugar, por excelência, de um tipo de experiência, na qual o poder transformador e criativo das representações colectivas se realiza na consciência dos sujeitos. ${ }^{5}$

Numa perspectiva filosófica, Kevin Schilbrack ${ }^{6}$, reforça a ideia de que as acções rituais são tratadas apenas como um veículo para o pensamento e defende que podem ser um modo de pensar, em si mesmo. A acção, assim como o pensamento e a sensação, são fontes de conhecimento. Schikbrack enuncia a importância de Ludwig Wittgenstein na legitimação de idiomas significativos per si. Uma linguagem que tenha as suas próprias regras, especialmente quando surge a partir de práticas, ou de formas de vida particulares, nas quais ela faz sentido:

Giving orders, and obeying them - Describing the appearance of an object, or giving its measurements Constructing an object from a description (a drawing) - Reporting an event - Speculating about an event — Forming and testing a hypothesis

Presenting the results of an experiment in tables and diagrams - Making up a story; and reading it Play-acting - Singing catches - Guessing riddles Making a joke; telling it - Solving a problem in arithmetic - Translating from one language to another - Asking, thanking, cursing, greeting, praying ${ }^{7}$. 


\section{Performance participativa}

De que forma um ritual torna actual, usando a expressão de Taylor, uma verdade "mais verdadeira"? Será que o potencial diferencial de um evento em particular, uma performance, consiste em intensificar a experiência de vida? E qual o nível de participação necessário para isso acontecer? E questões elaboradas por Eleonora Fabião ${ }^{8}$ : Que afetos e (de) composições uma ação performativa será capaz de deflagrar? Que afetos e (de)composições será capaz de bloquear? Estas são algumas das perguntas que dão início a este ensaio mas que também fizeram parte do processo de criação de Turning Backs, a peça elegida e em foco neste texto.

Turning Backs foi criada em 2016 numa colaboração entre Lígia Soares, Rita Vilhena e Diogo Alvim. É uma performance que tem como indispensável a voz e o corpo dos espectadores num dispositivo que os divide em dois grupos, sentados de costas uns para os outros. A proposta reflecte sobre o potencial do ser cultural e social, procura criar contextos onde o indivíduo se identifique e se transforme (ou finalmente não). Rita Vilhena, como foi referenciado é uma das co-autoras de Turning Back e autora deste ensaio. Vilhena gostaria de ser o Don Juan de Nietzche, uma rebelde, em que o conhecimento se apresenta como um dever, e procura desafiar os outros ao mesmo tempo que quer ser desafiada. A capacidade de conquistar conhecimento está para ela associada à ideia de participação, estar no meio da acção, no fazer. Quando Grotowsky fala do Performer ele explica: "Na tradição Hindu fala-se de vratias (hostes de rebeldes). Vratia é alguém que está no caminho de conquistar o conhecimento. Um homem de conhecimento tem ao seu dispor o fazer e não ideias ou teorias. O verdadeiro professor - o que é que ele faz pelo aprendiz? Ele diz: faz. O aprendiz luta para perceber, para reduzir o desconhecido ao conhecido, para evitar fazer. No próprio acto de querer perceber, ele resiste. Ele apenas pode compreender depois de fazer. Ele fá-lo ou não. Conhecimento é uma questão de fazer." 9

Concordando com Turner, a actividade cultural humana destaca-se justamente pela sua propensão performativa: “... As suas performances são, em certo sentido, reflexivas, na performance o sujeito revela-se a si próprio para si próprio" ${ }^{10}$.

Schechner defendia que a troca de espaço entre artistas e espectadores, e a exploração do espaço total por ambos os grupos, não tinham sido introduzidas no 'nosso' teatro por etnógrafos. Esse modelo estava mais perto de casa: as ruas. A vida quotidiana da rua é marcada pelo movimento e pelo intercâmbio de espaço; as demonstrações de rua são uma forma especial da vida da rua que dependem das aplicações mais elevadas dos regulamentos diários. Uma marcha com ou sem autorização, uma sanção oficial. Em ambos os casos, o evento é definido pelas regras mantidas ou quebradas. O uso cada vez maior do espaço público para as atividades ensaiadas (desde manifestações até teatro de rua) já desde os finais dos anos sessenta, foi informando o teatro 'indoor'. Steve Nelson, duas décadas depois de Schechner criar o conceito de Enviromental Theater, constatou que o conceito não era, então, uma novidade, e tampouco possuía a urgência de encontrar novas formas ou efetuar mudanças sociais e artísticas que caracterizaram muitos trabalhos ambientais nos anos 60 e início de 1970. A questão que Nelson ${ }^{11}$ sustentou na altura foi da participação da audiência ser crítica porque implicava não apenas uma relação física diferente entre ator e audiência, mas uma compreensão diferente do contrato de intérprete / espectador - do que é esperado e entregue por cada parte.

A participação não era simplesmente uma opção na década de 1960 - para muitos, era uma necessidade, a raison d'etre da performance em si. Schechner escreveu uma vez que a "responsabilidade" da audiência para responder de forma ativa ${ }^{12}$, era uma idéia muito distante e relativamente passiva (intelectualmente, se não fisicamente) em muitas performances contemporâneas. Turning Backs é um dispositivo coreografado onde as pessoas abremse fisicamente (pelo menos as costas) e a barreira entre ator e espectador funde-se, deixando de existir. A quarta parede dilui-se no espaço do espectador. Podemos afirmar que em Turning Backs o espectador é o corpo do espetáculo? E que corpo será este dirigido por um ecrã?

Turning Backs é um trabalho que coloca o público no centro da acção. É uma instalação cénica performativa, que combina a composição de texto, voz, movimento e dispositivos cénicos, para orquestrar, a partir de duas frentes opostas, duas linhas de espectadores pedindo a sua participação. Virados de costas uns para os outros, os espectadores constituem uma espécie de corpo coral. São comandados por dois vídeos, duas frentes de luzes, quatro fontes sonoras e duas cenas. É uma peça que visa a materialização do paradoxo: todos estamos incluídos na exclusão. Os espectadores representam juntos um mundo onde as realidades constantemente se opõem. "As duas linhas de assentos não têm costas e obrigam cada espectador a utilizar as costas de outro como encosto. Esta condição será também uma base para refletir que estar costas com costas é afinal encostar a alguém sendo que, esse alguém, é exatamente a pessoa a quem virámos as costas." ${ }^{13}$ Esta situação é reforçada na performance, com texto projectado para os espectadores lerem, com alegorias às codependências económicas, a questões de geopolítica, à repressão cultural face à assertividade da sociedade de consumo, à xenofobia e aos trânsitos.

Parafraseando Marshall McLuan: o ambiente é o produto; Os meios de encenação tornaram-se os fins. Poder-se-ia concluir que a forma é conteúdo ${ }^{14}$; Que a maneira pela qual algo é feito é inseparável do que se está a dizer. Isso poderia recair sobre o argumento da arte pela arte, usado para justificar a auto-absorção típica de muita performance pósmodernista. A questão da forma no Turning Backs não só propõe uma participação do público como sublinha 
a dependência desta, a partir de projecções, para a performance acontecer. $\mathrm{O}$ dispositivo cénico depende da voz de pelo menos duas pessoas sentadas de costas com costas. Os espectadores são o corpo da performance e quanto mais pares estiverem sentados mais massa, voz e oposição é experienciada.

A peça foi escrita em Inglês por Lígia Soares em colaboração de Rita Vilhena e Diogo Alvim. Não foi traduzida para português, porque foi criada para um público internacional (dentro e fora do país). Para reforçar Wittgenstein, provavelmente a peça seria mais afectiva se fosse reescrita no idioma do país onde fosse apresentada. A interpretação dos conteúdos projectados nos ecrãs são lidos, cantados ou sussurrados pelo espectador, e são de tal forma poéticos e ricos de subtilezas linguísticas e fonéticas que muito se ganharia se os autores fossem capazes de fazer traduções/re-criações dos textos. Mas o que é transversal a essa linguagem e ao mesmo tempo central neste trabalho é a condição do espectador. Em Turning Backs a projecção é o mecanismo principal de comunicação; todo o espaço é usado para a performance; o espaço todo é usado pelo espectador; e todo espectador pode/deve ser o performer da peça. Em Turning Backs verifica-se a coligação entre performer e espectador, tendo a projecção como o único mediador.

De seguida vamos sistematizar a origem do projecto para melhor compreendermos o processo criativo da linguagem utilizada na projecção.

A origem do projecto nasce na sequência de uma anterior colaboração entre Rita Vilhena e Lígia Soares com um dueto intitulado de The Lung, estreado em Janeiro de 2016. Vilhena e Soares partilham da questão da participação do espectador. Os seus projetos em conjunto procuram criar espaços performativos a partir da presença dos corpos e da ação, independentemente se esta pertence ao performer ou ao espectador. A presença do espectador é-lhes tão interessante e tão fortemente significativa como a condição do performer. O projecto The Lung começou com a premissa: tanto o performer quanto o espectador respiram. Partiram da observação das suas próprias costas nuas a respirar e, encenando-as como dois órgãos de um mesmo organismo, criaram um movimento pulsante e um texto baseado na vocalização de palavras opostas através de um sistema simples, e aparentemente involuntário (como o sistema respiratório). Ironizando sobre a naturalidade das palavras e revelando a dialéctica verbal como o motor do desequilíbrio no seu acentuar de opostos: weekend! week - end, $U$ - eek, u - e, e - u, y - you, you dick, you - pussy, you - bitch, you - son, you - mother, you - holly, father - holly, just like your mother - just like your father, etc ${ }^{15}$. A repetição tanto de palavras como movimentos conduzia o espetáculo a um estado hipnótico ou meditativo, e o espectador poderia ligar-se facilmente ou sentir uma forte resistência àquela espécie de mantra, conceptual e minimalista, numa simbiose que apontava para a vivência mimética das coisas.

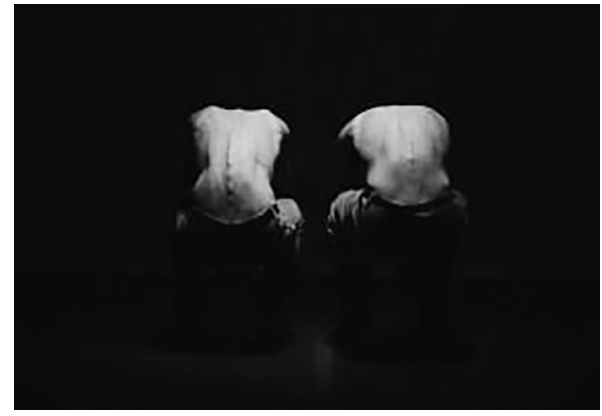

The Lung - Teatro Rua das Gaivotas 6, Lisboa 2016. (C) João Felipe Dias

Durante o processo criativo da performance The Lung, Vilhena e Soares abandonaram a proposta de integrar o espectador no espectáculo como corpo performativo. Esta proposta foi resgatada com a criação de Turning Backs. A metodologia e a linguagem própria que foi criada para o dueto The Lung iria servir para a dialética da performance Turning Backs. A estética minimal criada para o The Lung, de palavras opostas e justapostas através de sistemas simples, permite articular ideias através da sua materialidade no corpo ou na voz, sem as intelectualizar e sem as concluir: $e-u, u-e, y-u, y-y o u, y o u-y o u$. As criadoras pressupõem que esse tipo de estado mais primário da linguagem inclua mais pessoas, como se pudéssemos de novo criar jogos cantados, lengalengas, missas, ou uma cultura comum, uma representação do mundo à qual todos estamos vinculados.

\section{TURNING BACKS}

Para Arendt ${ }^{16}$ a pluralidade do colectivo enquanto pluralidade humana é a condição básica da acção e do discurso que tem o duplo aspecto de igualdade e diferença. A igualdade é a capacidade de se entenderem, os antepassados e as necessidades das gerações vindouras. Diferença, a necessidade do discurso ou da acção para se entenderem. A força do colectivo seria assim a de multiplicar as forças individuais. Sozinhos ficamos livres mas não podemos exercitar a nossa liberdade (leia-se a de participar). E é nessa participação que agimos e tomamos consciência do exercício da nossa liberdade. Agir é tomar iniciativa, iniciar, imprimir movimento a alguma coisa.

Em Turning Backs a participação num sistema e a acção de dizer, tornaram-se assim o próprio objecto de crítica e reflexão sobre a constituição de um discurso globalizado. O objectivo principal está na forma de passar uma acção para as mãos (voz ou corpo) do espectador e fazê-lo compreender-se como igualmente integrante e responsável por uma obra e pela representação do mundo. No final os espectadores ficam mesmo, finalmente, com as costas a ferver. Existe um paralelo à arte situacionista como forma de representação ou de celebração cultural. Uma 
ideia de representatividade que se afasta da noção de espetáculo como consumo cultural para se aproximar de ideias de incorporação de acções representativas, independentemente da nossa identificação ou não com estas. É preciso que seja entendido que neste projeto o objectivo principal não está nas capacidades performativas ou no protagonismo do intérprete, mas sim na importância de utilizar a performance e a criação artística como forma de passar uma ação para as mãos (voz ou corpo) do espectador e fazêlo compreender-se como igualmente integrante e responsável pelo espetáculo.

Nos vários momentos da criação e apresentação: Mala Voadora no Porto (festival Happy Together), Devir-CAPa em Faro, Alkantara em Lisboa e, no Rotterdamse Schouwburg em Roterdão (Holanda), Vilhena teve oportunidade de fazer, de forma pouco formal, algumas perguntas aos espectadores após a participação. O trabalho de campo neste aspecto foi pouco incisivo e sem algum método científico pois ainda não se tinha vinculado o objectivo de fazer um estudo sobre o Turning Backs. Mas fica a nota que nas próximas apresentações Vilhena poderá ter esta oportunidade e aprofundar as reacções dos espectadores. Contudo, podemos deixar as observações levantadas. Cada grupo de pessoas que ia assistir ao espetáculo trazia expectativas diferentes. A maior parte das pessoas entrevistadas não tinha conhecimento a priori do que iriam assistir: uma instalação performativa mediada por projecções, e o pressuposto de participarem - conceito explicitamente enunciado na sinopse do espetáculo. A apresentação no Rotterdamse Schouwburg, o teatro municipal que trabalha directamente com a estrutura de produção da qual Vilhena fez parte durante quatro anos, foi particular. Vilhena cria dança contemporânea, nas suas peças ela coloca bailarinos, actores e músicos em cena, o público em Roterdão está habituado com esta dramaturgia. Vilhena sentiu uma grande expectativa por parte dos espectadores e recebeu feedback dos presentes: tão depressa aceitavam a proposta e/ ou desiludiam-se porque o trabalho não entrava, na sua sensibilidade ou conhecimento, num conceito de dança contemporânea. Cada grupo reagiu de forma muito particular e própria. Algumas pessoas depois da performance, ao serem questionadas sobre o Turning Backs, acharam que a proposta ia para além do seu aspecto lúdico e sentiram que por um lado tinham que negociar com as restantes pessoas que partilhavam a mesma fila que elas, e por outro a importância que tinha escutarem as outras pessoas que estavam na outra fila, de costas para elas. Relembre-se que o público está dividido em dois grupos de espectadores distribuídos em duas filas, sentados no mesmo banco corrido, encostados de costas com costas com o outro. A performance mediada pela projecção deixa o espectador no escuro como num cinema, com uma enorme tela à sua frente (uma de cada lado, uma em cada frente). Pelo modo como o espectáculo começa, com didascálias, o espectador entende que o proposto é de participar e que essa responsabilidade lhe cabe.

As pessoas estão sentadas às escuras e todas na mesma condição de espectador mas a expressão que cada um dá varia, por exemplo: ler em voz mais alta ou mais baixa, em uníssono ou nos vários tempos de delay. Os criadores da peça, Rita Vilhena, Lígia Soares e Diogo Alvim, fizeram um registo áudio de todas as apresentações e, se um dia existir um contexto pertinente, vai ser interessante fazer dessa documentação material de reflexão sobre as diferentes participações a partir de um mesmo guião. Turning Backs é uma instalação performativa que visa a sua concretização na situação do espectador e na articulação complementar dos dois lados da cena. A sua partitura funciona como algo que não está acabado mas que induz à participação das duas linhas de pessoas, numa espécie de coros que envolvem os seus corpos, deixando ecoar através do espaço a voz, e através das costas a respiração que atravessa e liga essa fronteira que os mantém de costas e invisíveis entre si. Foi assim que os autores criaram um sistema de partituras ou instruções que expressam ideias como: o que não representamos para outros; o que representamos; em que medida estamos dependentes dos outros nesta sociedade; em que medida os outros estão dependentes de nós nesta sociedade; de que é que somos o negativo, de que é que somos o positivo; ao que é que nos apetece virar as costas; o que é que tem as costas voltadas para nós; se fôssemos o contrário de nós próprios o que seríamos, entre outras que levam as pessoas a dizer palavras que ignoram ou absorvem o lado que se Ihe opõe. O discurso levantado teve como base métodos de composição de linguagem baseado em enumerações, ritmos, jogos associativos, repetições, transformações fonéticas, procurando a voz individual, reivindicativa, poética mas evitando a psicologia e a exposição pessoal, exemplo: I love you - I love you too, Do you? - I do, Do you - Love me, Do you - Hurt me, Do you - Need me, Do you - Fuck me, Do you - Do you, No - Yes, Not - you, Not - me, You and - Me and, You and - Me, We - We, Why We, Why - White, Black - White, Black - Out, Back out - White in. ${ }^{17}$

Não só a voz mas também o corpo foi meticulosamente coreografado, e evidente nesta proposta, como anteriormente referido, de integrar o espectador no acto performativo. Em Turning Backs o público senta-se no centro de cena, no palco ou no espaço de galeria/museu, dependendo do programador. O corpo está em constante negociação com outro corpo que lhe serve de apoio e que ao mesmo tempo o informa do que se está a passar nas suas costas, o corpo do outro. Esta relação é recíproca e co-dependente. 


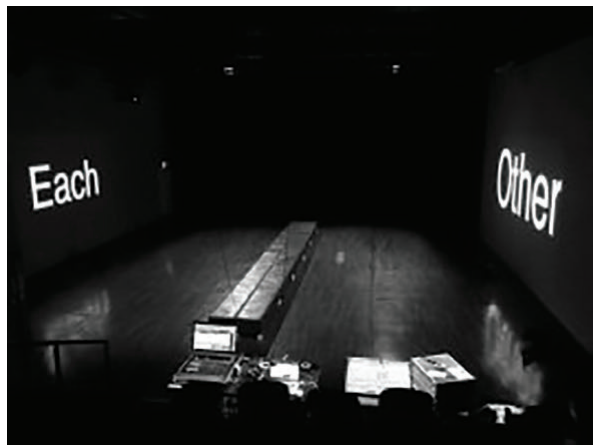

Turning Backs - Rotterdamse Schouwburg Maio 2017. @ Diogo Alvim \& Rita Vilhena

\section{Considerações finais}

O uso do conceito de performance na antropologia tem sido tratado de modo diverso, a partir das abordagens de Turner e Schechner entre outros. Tomemos aqui o seu sentido genérico, partilhado pela maioria dos autores, de modo de comunicação cuja essência demarca um acto de expressão (sentido/ significado e forma) e requer a consciência do mesmo e do(s) seu(s) executante(s), assim como a sua apreciação por uma audiência. Como toda e qualquer actividade humana, a performance é conceitualizável - a sua forma, o seu sentido e a sua função podem ser social e culturalmente definidos. Victor Turner ${ }^{18}$ sugeria que as culturas adquiriam maior visibilidade e permitiam aos seus membros a consciência de si mesmos nas e pelas performances rituais e teatrais. Reconhecemos o carácter eminentemente reflexivo das performances culturais. E fica o desejo que as performances potencializem de forma alegre e positiva as relações humanas. E alegre deve ler-se por, o aumento de potência no encontro, aumento de grau de aç̧ão e paixão no encontro.

Em Turning Backs criam-se palavras e movimentos que se repetem sem que tenhamos a noção do que é que realmente representam ou mesmo representamos na sociedade e na relação com os outros. A participação num sistema e a ação de dizer, tornam-se assim o próprio objecto de crítica e reflexão sobre a constituição de um discurso globalizado e massificado por sociedades capitalistas, mas será mesmo esta a forma de intensificar a presença humana, a de the colocar palavras na boca no escuro, à frente de um ecrã?

Observa-se num processo de tentativa-erro desde The Lung a tentativa de confrontar o contrato: espectador - performer. "Confrontação" é um termo tão endêmico para o discurso social / político / estético dos anos sessenta, e como se dum cliché se tratasse, ainda tão atual. A necessidade de mudar, provocar, alterar ou transformar o espectador, seja por herança ou por resistência ainda está presente nos modos de criação destes artistas. $O$ vínculo entre os argumentos de um fundo de "arte" (arte pela arte) e a proposta de arte para promover encontros positivos (ou felizes -
Spinoza) faz do Turning Backs um indicativo do nosso tempo. Vilhena, Soares e Alvim foram ao encontro de representações identitárias, transversais e inclusivas para uma criação artística, um momento que visa tanto a responsabilização como a empatia pelo o outro. A peça trabalha assim do particular para o global, com fim à inserção crítica num mundo que, ao se querer global, mascara as suas diferenças. E tenta promover uma ideia de diálogo entre uma obra e o público levando o espectador a confrontar-se com uma espécie de co-dependência entre espectáculo e espectador. Ou talvez seja só uma estética de trabalho, um meio de entrada (e sem saída).

Turning Backs aborda a dança e a performance através da disposição criteriosa do corpo do espectador. Confrontando a sua situação com os outros espectadores e com a temática da peça. Explora a partir de uma projecção o movimento que antecede o discurso, ou que leva ao discurso. O movimento como a expressão silenciosa de uma realidade que apela à mudança. Mas ficamos desconfiados com o desconforto desta expressão restrita e com o dispositivo que, ainda assim, dita as coisas que temos que dizer.

Este trabalho é financiado por Fundos Nacionais através da FCT - Fundação para a Ciência e a Tecnologia no âmbito da unidade I\&D 472 (UID/ EAT/00472/2019)

\section{Nota Finais}

${ }^{1}$ (Taylor, (2002, 3)

2 (Turner, 1987b, 98)

3 (Fabião e Osorio 2018,3)

${ }^{4}$ (Turner, 2005, 69; 1987, 77)

${ }^{5}$ (Durkheim, 1996)

${ }^{6}$ (Schilbrack 2004)

${ }^{7}$ (Wittgenstein apud Schilbrack 2004, 4)

${ }^{8}$ (Fabião e Osorio 2018, 3)

9 Nota que acompanhou o texto "Performer" na brochura publicada pelo Workcenter em Pontedera, Itália. Uma versão deste texto - baseada numa conferência dada por Grotowski foi publicada em Maio 1987 pela Art-Press em Paris.

10 (Turner 1987, 81, tradução minha)

11 (Nelson1989, 72-94)

12 (Schechner 1973,19)

13 (Lígia Soares, Turning Backs folha de sala, 2017)

14 "the package is the product; the means of staging have become the ends. The point could be made that form is content." (McLuhan, 1994, tradução minha)

${ }^{15}$ Exemplo retirado do guião da performance The Lung, 2016 Lisboa.

${ }^{16}$ (Arendt 2000, 189)

17 Texto retirado do guião de Turning Backs, 2017 Lisboa.

18 (Turner 1982)

\section{Bibliografia}

Arendt, Hannah.2000. A condição humana. 10. ed. Rio de Janeiro: Forense Universitária. Burzyńska, Anna R. 2016. Joined Forces - audience participation in the theatre, Performing Urgency \#3, A house on fire publication.

Deleuze, Gilles e Félix Guattari. 1991. Percepto, Afecto, Conceito, O Que É a Filosofia, traduzido por Bento Prado Jr. e Alberto Alonzo Munoz. Colecao TRANS, Editora!34. 
Fabião, Eleonora e Luiz Camillo Osorio. 2018. "Conversa com Eleonora Fabião, por Luiz Camillo Osorio" in Pipa - a janela para a arte contemporânea brasileira http://www.premiopipa.com/2018/03/conversa-comeleonora-fabiao- por-luiz-camillo-osorio/. Acedido em 10 de Maio 2019.

Grotowsky, Jerzy. 1990. "Performer" traduzido por Thomas Richards, e tradução para português de João Garcia Miguel. Paris: Art-Press.

Malzacher, Florian. 2015. Not Just a Mirror- Looking for the political theatre of today. Performing Urgency \#1, A house on fire publication.

McLuhan, Marshall. 1964. Understanding Media: The Extensions of Man. Nova lorque: Mentor.

Nelson, Steve. 1988. "Redecorating the Fourth Wall: Environmental Theatre Today", The MIT Press, TDR, Vol. $33 n^{\circ} 3$.

Pais, Ana. 2017. Performance na Esfera Pública, Orfeu Negro.

Rancière, Jacques. 2010. O Espectador Emancipado. Traduzido do francês por José Miranda Justo, Orfeu Negro.

Schechner, Richard e Appel Willa. 2005. By means of performance, theatre and rituals. Estados Unidos da América. www.news.cornell.edu/Chronic. Acedido em Novembro 2017.

Schechner, Richard. 2006. Performance studies: an introduction, $2^{\text {a }}$ edição, London: Routledge.

Schechner, Richard. 1973. Environmental theater, London: Applause.

Schechner, Richard. 1968 "6 Axioms for Environmental Theatre", The Drama Review: TDR, Vol. 12, $\mathrm{n}^{\circ}$ 3, Architecture/Environment. www.jstor.org/stable/1144353. Acedido em Novembro 2017.

Taylor, Diana. 2002. Translating Performance. Modern Language Association. www.jstor.org/stable/25595729. Acedido em Setembro 2016.

Turner, Victor. 1985. On the edge of the Bush: anthropology as experience. Tucson, Arisona: The University of Arizona Press. www.edgecentral.net/turner. Acedido em Dezembro 2017.

Turner, Victor. 1987. "The Anthropology of Performance" in The Anthropology of Performance, Nova lorque: PAJ Publications.

Turner, Victor. 1995. The Ritual Process, Structure and Anti-Structure. Nova lorque: Aldine de Gruyter. 